\title{
Editorial
}

\section{THE QUEEN ALEXANDRA MEMORIAL CHAPEL}

From time to time it is opportune to write about subjects of distant but not direct medical interest. This is such a time because the story of the Hospital Chapel on the site of the old Queen Alexandra Military Hospital at Millbank is in danger of being lost to posterity amidst the demolition and redevelopment of the hospital site.

The chapel was given to the Hospital by an anonymous donor, later identified as Major Francis $R$ Gregson, whose intention was that it should be committed to the care of the authorities for ever in commemoration of the officers, non-commissioned officers and men of the RAMC, and sisters of the Army Nursing Service, who died in the South African War, 1899-1902. The chapel was formally opened at a service of dedication on Thursday 24 June 1909 in the presence of King Edward VII and Queen Alexandra.

The cloak of Major Gregson's anonymity was torn aside in 1911 when a controversy arose concerning the design of a memorial window to Florence Nightingale. The window was presented by Miss Becher, the then Matron in Chief, on behalf of the QAIMNS but Major Gregson objected to the design. Despite much argument no resolution of the disagreement could be achieved. In the end the Chaplain General wrote to Major Gregson and concluded with the words "women are different to us men and allow sentiment and feelings to overcome reason." The window was installed. After Major Gregson's death in France during World War I an alabaster tablet was erected on the wall to record "his munificent gift of this Chapel in 1909."
Between the wars and until the hospital closed in 1977 the Chapel was in regular use; there must be thousands of past patients and hospital staff who will remember with gratitude its peace and tranquillity. Although the exterior of the building has no great claims to architectural merit the interior is a gem of early 20th century memorabilia, a period collection rarely seen in such profusion in one place. Furthermore such a collection, evoking so many memories for visitors concerned with the early days of the RAMC and the QARANC, is unique as a treasured record of a now forgotten but truly remarkable era in the history and evolution of the Army Medical Services.

Although the hospital has been closed for 7 years the Chapel continues to be well looked after and also to play a small part by way of weddings and Christmas carol services in the spiritual life of the Medical Services, particularly for those members stationed at Millbank where the College Chaplain is ever anxious to continue and perpetuate the Chapel's active role.

Sadly the Chapel now faces the threat of demolition in the face of the redevelopment plans for the Tate Gallery. Although the Chapel Committee, headed by the GOC London District, and at the behest of the Director General Army Medical Services, is doing what it can to preserve the structure, or at least, to ensure a safe home for the many and valued memorials, the prospects for success are not propitious. It is fitting that, come what may, the history of this sentimental building should be recorded and not forgotten. 